\title{
Qualification Profile of University Professors in Business and Information Systems Engineering (BISE)
}

DOI 10.1007/s12599-013-0252-x

\author{
The Authors \\ Prof. Dr. Peter Loos ( $\varangle)$ \\ IWi at DFKI \\ Saarland University \\ 66123 Saarbruecken \\ Germany \\ loos@iwi.uni-sb.de
}

Prof. Dr. Dr. h. c. mult. Peter Mertens

Prof. Dr. Torsten Eymann

Prof. Dr. Dr. h. c. Rudy Hirschheim

Prof. Dr. Burkhard Schwenker

Prof. Dr. Thomas Hess

Published online: 2013-02-20

This article is also available in German in print and via http://www. wirtschaftsinformatik.de: Loos $P$, Mertens P, Eymann T, Hirschheim R, Schwenker B, Hess T (2013) Qualifikationsprofil für Hochschullehrer der Wirtschaftsinformatik. WIRTSCHAFTSINFORMATIK. doi: 10.1007/ s11576-013-0352-8.

(C) Springer Fachmedien Wiesbaden 2013

\section{Introduction}

The tasks of university professors include teaching, research, and university selfadministration. Therefore, various skills and qualifications are necessary. Young researchers need to know which qualifications are important to get a chance to become professor. In this context, publications in high-ranking journals, which are rated according to different indicators, gain increasing importance in our scientific discipline (Loos et al. 2010). Meanwhile, there are approaches to predict scientific impact based on the publication record of a researcher (Acuna et al. 2012).

However, other factors are also essential for the appointment procedure. Many job descriptions for a professorship in the field of BISE in the German- speaking countries mention "acquisition of external funding" as a criterion. Is this a useful criterion or is it an expression of lack of funding via the university budget? On the other hand, practical experience in the field of industry or services, or applications with a sole industry background are rarely wanted. However, for a scientific discipline the research field of which is the application of information and communication technology in business, shouldn't practical experience be a more important criterion? Isn't a practical background also important for relevant research and teaching? Is the noticeable shift in the required skills set a necessary consequence of the establishment of our scientific discipline, or should it be a matter of concern?

Therefore, the following questions have to be addressed in the discussion group:

- What skill does a university professor in Business and Information Systems Engineering have to have? Is there a ranking of the required skills possible?

- How important should practical experience in the appointment procedures of universities be? How important is the level of acquired external funding as a criterion?

- What are the differences between a required skills set in the field of BISE and other research fields such as computer science and business economics?

The following researchers have agreed to participate in this discussion (listed in alphabetical order):

- Prof. Dr. Torsten Eymann, Universität Bayreuth

- Prof. Dr. Thomas Hess, LMU München

- Prof. Dr. Rudy Hirschheim, Louisiana State University

- Prof. Dr. Dr. h. c. mult. Peter Mertens, Universität Erlangen-Nürnberg

- Prof. Dr. Burkhard Schwenker, Roland Berger Strategy Consultants

Peter Mertens analyzed 55 recent job postings for BISE professors in German speaking countries and compared the observed skills to the so-called "decathlon"skills of a professor. He accesses that ex- cellence in teaching and knowledge transfer from research into business practice are of less importance in the described skill sets. Even work experience is not required, despite the fact, that it would be a desirable skill in our field and in an academic environment in general. Overall, Mertens wishes for a more balanced consideration of all the different criteria.

As the ombudsman for young academics of Wissenschaftliche Kommission Wirtschaftsinformatik, Torsten Eymann describes the view of junior researchers. He found out that many are insecure because they fear to be solely judged by their publication record in the application procedure. Their management skills to master all the responsibilities of leading a chair seem, however, to be of minor importance in an application procedure. Regarding "acquisition of external funding”, Eymann recommends a balanced portfolio strategy. He concludes that a BISE skill set does not fundamentally differ from a business economics skill set or a computer science skill set.

Rudy Hirschheim describes the development and changes of the US-American job market for IS professors since the early 1970s as well as current issues of the local IS programs. He states that the American industry is more interested in graduates of IS programs than in the results of IS research. He advocates the academic world and the practical world to mingle more, e.g., researchers should work in industry during lecture-free times and people from industry should participate more in $\mathrm{PhD}$ programs. Furthermore, researchers should increase efforts to acquire external funding.

Burkard Schwenker is of a contrary opinion. He advocates a stronger theoretical focus in BISE at universities. According to him, only theory-driven teaching equips graduates with the necessary skills for the working world. Complex issues cannot be approached with empirical knowledge from case studies. Theory-driven teaching should be supplemented with a "studium fundamentale" and broadly-based subject-specific 
course content. Not training is the goal of a university program but education. Based on that, Schwenker highlights the major importance of the theoretical and methodological skills particularly for university professors.

The primary skill, according to Thomas Hess, is the support of scientific progress. Consequently, high-quality scientific publications of university professors are very important and should be rated via indicators such as journal rankings and impact rankings. Furthermore, a researcher's skill set should be extended with the ability of researchoriented teaching, the ability to interact with the business world, and management skills to run a department.

Overall, there is a common agreement on the importance of excellent research - documented by high-ranked publications - as a necessary skill for an academic career; further qualification skills, however, are assessed with different levels of importance. If you would like to comment on this issue - or on any other article in BISE journal - please send your comment (2 pages maximum) toloos@iwi.uni-sb.de.

\section{Prof. Dr. Peter Loos IWi at DFKI Saarland University, Saarbrücken}

\section{The Requirements for University Professors of Business and Information Systems Engineering (BISE) as Stated in Job Advertisements}

\subsection{The Problem}

There are no simple answers to the question as to the requirements since the criteria depend on the "mission" of the position to be staffed. Examples:

- The university is looking for a professor for a chair with a long tradition, considerable resources and an affiliated research institute. This professor must be experienced in maintaining contacts to private firms and with networking.

- A junior professor shall help to cope with a temporary overload.

- A professor is appointed because he has a long list of publications which helps the school in specific rankings.

For some time, rankings based on papers in journals have strongly influenced the appraisal of university professors. As it could be expected, presently we see more concerns.

One group prefers to view the holistic personality with a magnitude of talents, capabilities, knowledge and goals which can be used - in hard work - to support the students, the science, the economy and the society, in other words the stakeholders of the university system. According to the special features of Business Information Systems Engineering (BISE), which is interdisciplinary and influenced by management, computer science, engineering, and social science, a good BISE professor has to pursue about ten functions ("decathlon") (Mertens 2011).

We do not know of any research studying the requirements defined by the stakeholders, especially the potential employers of graduates. So it seems appropriate to employ the descriptors that universities themselves use when they draft a job offer for a professorship in BISE.

\subsection{Method}

We collected all job advertisements for WI-professors at universities in the German speaking area from 2010-01-01 until 2012-10-31, spanning 34 months. All in all, 55 items were found.

The requirements mentioned in the texts were divided into 13 groups. We only considered criteria that were different from advertisement to advertisement, not obligatory clauses regarding, e.g., gender or age of applicants.

Moreover we noted some peculiar requirements like "We expect distinctive presence at the university"(!).

\subsection{Findings}

Place 1 goes to the attribute "Acquisition of third party funds" (37 entries). Mostly the wording used is "Experience with the acquisition". The realization or the management of the projects is only mentioned on rank 5 (16). To put it bluntly: As soon as the money is secured, the goal seems to be achieved. It is not important how efficiently the resources are used.

On position 2 we find the cooperation with international partners in research projects (26). The third rank is taken by the readiness to teach lectures in English (22). These two descriptors have to be regarded in connection with the internationalization (see Chap. 4). This also becomes manifest in position 6 "International scientific experience" (14).
Not until place 4 we have high ranking papers (20).

Teaching requirements are expressed by wordings such as "Evidence of didactic expertise" (12) and "Excellence in teaching and research" (10). They follow on ranks 8 and 9, respectively. We will see in how far forecasts of politicians will come true which predict that a special pact between the states and the federal government of Germany to promote academic teaching will result in the ambition of professors to give teaching the same relevance as research. The German private institute CHE (Centrum für Hochschulentwicklung = Center to develop universities) has analyzed how the billions of Euros of this pact were used up until now. Fischer and Haerder wrote in 2012 that the increasing number of students was mainly being compensated by hired lecturers, and that the importance of professors is declining.

An important group of the stakeholders, private firms, is very interested in teaching competence. As an example let us mention an initiative of the German Association for Machine Building (VDMA = Verband Deutscher Maschinen- und Anlagenbau) which is sponsoring teaching at university level in order to reduce the percentage of students resigning in their first semesters.

It is not before rank 11 that we find the readiness to technology transfer (6). This is remarkable since for other institutions such as local firms, authorities and media the benefits of research results of the local universities for the companies in the area are of high impact.

\subsection{The Criterion "International"}

The impact of the international relations of the applicants in a broader sense can be estimated by clustering the descriptors "International scientific experience" (14), "Doing research with international reputation" (14), "Lectures in English" (22), "Integration in the international research within the discipline" (3), "Cooperation with international partners in research projects" (26), and "Applications from foreign countries" (8). Regarding this entity we recognize the paramount significance ("conditio sine qua non"). 


\subsection{Relations to the "Decathlon" Framework}

As a reference we used the Decathlon framework (Sect. 2.1). Of the ten disciplines, the following ones are not mentioned in our sample: textbooks/teaching materials - transfer of research results to practice/technical books - transfer to politics and society/participation in committees of government and administration/appearance in the media - promotion of the region's economy/spin-offs self-administration of the scientific community - education of the young academics. It is a cause for concern that writing textbooks and technical books has become almost insignificant in the last years.

Comparing our analysis of the job offers with the requirements that are necessary to meet the ten criteria, we find:

- The capability to teach in an unfavorable environment (e.g., extreme numbers of students in the lecture hall and in the examinations) is not mentioned explicitly. However, if a university professor is able to perform well in this regard, he will serve the scientific community well since he is organizing good education with a low budget.

- Experiences acquired as an employee of a firm are not a criterion in our sample. In my opinion it is a detriment if a professor becomes a lifelong teacher of BISE without having been in business. But this might be disputed. However, a situation could arise where all students come from practice, e.g., the participants of an MBA program. The only person in the room not possessing this kind of experience could be the professor. Would a university appoint a professor as head of the department of cosmetic surgery who is a luminary in culturing artificial skin but never transplanted a piece of skin to the face of a disaster victim?

- Articles in journals for practitioners and similar media of knowledge transfer such as papers for congresses with respective audience or technical books do not possess a high reputation (Buhl et al. 2012). I have experienced several situations where members of a scientific committee suggested to simply neglect these accomplishments when evaluating and ranking applicants. Gill and Bhattacherjee (2009) write: "Based on this assessment, we observe that the degree to which MIS is informing its key external clients - practitioners, students and researchers in

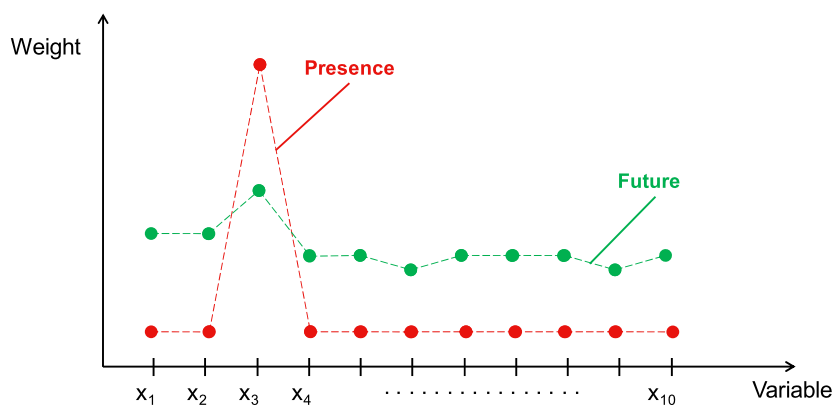

Fig. 1 Weighting of the variables (sketch)

other disciplines - has declined over the years".

- The knowledge transfer to private firms and to public administration by spin-offs seems to be of paramount relevance for a discipline like BISE, at least for its design-oriented branch. Above all it ensures that investors in academic research will earn a return.

\subsection{Proposal of a Modified Procedure}

- A professional society compiles a checklist with the criteria, e.g., on the basis of the "Decathlon framework".

- The school or a committee of the institute allocates weights to the criteria. This weighting depends on the situation or the special mission of the chair to be staffed (Fig. 1).

- After analyzing the applicant's documents and presentations, the committee calculates a ranking score.

- The boards of the university resolve to use the ranking as a decision aid.

\section{Portfolio Strategy for Junior Academics}

In my position as an ombudsman for young academics in the "Wissenschaftliche Kommission Wirtschaftsinformatik" in the VHB (scientific committee business and information systems engineering in the association of management scholars), I quite often face questions like the ones asked in this discussion. The working days of those who wish to be appointed for life are more than filled with a mixture of teaching, organization, acquisition of funds, implementation of acquired research projects, and not least, the writing of publications.

When applying for a position, it is a great concern not to be recognized as a manager-scientist who can successfully meet all these challenges, but to be reduced to an author-scientist, solely measured by his publications and their influence. The different conditions at the universities give reason to fear that later competitors for a professorship may have more time to publish and put less effort into management. This fear regarding different starting conditions concerns large and small universities, domestic junior academics versus junior professors, assistant professors and post-graduates in foreign countries versus all domestic careers. My own statistical survey of the recruitment practices in Germany between 2006 and 2011 shows that of 44 offered lifetime professorships 17 were given to domestic junior academics, 12 to junior professors, and 7 to assistant professors from abroad. This provides no indication as to which path of career is dominant.

It is indeed a fact that the challenges for a professor at a university are manifold, not only in the field of business and information systems engineering (BISE). Part of these requirements results from differing manager qualities called for in various academic markets. They include establishing and maintaining industrial contacts, combined with practical experience and acquisition of third-party funds. This now is exactly where BISE scientists have better chances and opportunities than scientists of other disciplines. Considering finite working time, however, funded research competes with, e.g., the writing of publications, so the young academic finds himself in a dilemma. What marginal utility lies in yet another publication, which benefit can be gained from another research request or a practical project?

Decisive for the young academic is the opportunity to present himself before a selecting commission. In a selection procedure two decisions are taken by the commission. The required information for each is obtained in its own way. The 
first decision concerns a selection among the incoming written applications aiming to detect interesting candidates and to invite them to give a lecture of application. During this procedure the interest mainly lies on the ability to play the part of the author-scientist. This is not astonishing, as on the one hand publishing efforts display an international standard, easily measured and described to anyone inside or outside the institution. On the other hand the written form of an application hardly offers a chance to compare candidates and arrive at a well-founded appraisal of the additional requirements.

The second decision concerns the selection of the thus short-listed candidates with the goal to attain not only an excelling author-scientist but a managerscientist as well; however, always under the primacy of superior research merits. Only in this situation will a commission conduct differentiated comparisons between the candidates and look at different achievement profiles. Today, sciences cannot be pursued by one person alone, and within a faculty and a university there are organizational tasks regarding research and teaching, which in the long run nobody can elude. Proven experience of a candidate in application procedures for DFG (the German national science foundation) graduate colleges or research groups, the implementation of industrial projects or the management of EU project pools may be of the same importance as excellent teaching accomplishments. The manager-scientist is the role which other members of the faculty will have most contact with in later everyday work.

What still remains is the question of how important it is to gain third-party funds, especially for BISE specialists. It would be wrong to build a career as a BIS professor on the function of a procurer of third-party funds, even though this is actually simpler than in other disciplines. A faculty whose one part does the publishing whereas the other organizes teaching and procures funds is on the way from a community of equals (from the Latin facultas = qualification) to a hierarchy of scientists graded in $\mathrm{A}+$, A, B, C and so on. Such a differentiation also exists regarding the source of thirdparty funds, where many research universities value grants from the DFG above all others, especially above funds from industrial projects. Advice here can only point to the direction of a portfolio strategy in which the own particular potency corresponds to the origin of funds.
In what way now does the requirement profile of the future BISE lifetime professor differ from that of his colleagues in economics and informatics? At the best in none. An excelling scientist with managerial qualities will find his way in all three fields, even though faculty culture weighs particular qualities differently. $\mathrm{He}$ should not try, however, to fit the profiles on all three fields at the same time; they have grown to be too different by now.

\section{Prof. Dr. Thorsten Eymann Universität Bayreuth}

\section{The Changing Face (and Fate) of the IS Professor: A US Perspective}

I have been the $\mathrm{PhD}$ Advisor for about two decades now at two different universities: University of Houston and Louisiana State University. Getting students to come into the $\mathrm{PhD}$ program has not been a particularly difficult task. A doctoral degree is society's most elite and distinguished degree. This terminal degree designates the holder as one of the most knowledgeable persons on the planet in their specified area. In discussing the degree with potential students, I ask them 'what do rock stars, professional athletes, and university professors have in common?' To which my response is 'they all get paid for doing what they probably would be doing even if they weren't paid. In other words, they get paid handsomely for doing something they love'. After such a compelling argument, it is little wonder the prospective $\mathrm{PhD}$ student is convinced this is what they should be doing. In the US, a PhD is the 'union card' for being a professor. If one wanted to be an IS professor, one needed a $\mathrm{PhD}$ in information systems (or some related discipline).

In the 1990s, universities were dying for IS professors. The IS discipline had grown steadily since the early 1970s with greater and greater numbers of students wanting to take courses in information systems. This created a demand for IS professors, and concomitantly, demand for the IS PhD. The problem was there was an insufficient number of $\mathrm{PhD}$ programs and insufficient faculty who could actually teach in these IS $\mathrm{PhD}$ programs. It got so bad that several universities (Indiana and Minnesota among others) developed 'conversion programs' to take individuals who had PhDs in other disciplines and 'converted' them to IS. These conversion programs were typically short programs which fast-tracked and jump started individuals in the field of information systems; the idea being that universities needed faculty (who had to have PhDs), these individuals had PhDs, so all they needed was the 'requisite' knowledge of IS. Of course, the issue of 'what constituted the requisite knowledge' and whether such knowledge could be acquired in a short program was a source of considerable contention. But the market of IS professors was hot and we needed to take folks wherever we could get them. The fact many of them had little to no Business background, and little to no knowledge of the IS practitioner was clearly not ideal. This era produced a considerable number of IS professors who had no real knowledge of the IS professional/practitioner, nor were they rewarded for such knowledge. Rewards were given based on scholarly research publications. This trend is still common today. Because of the reward system, IS academia, has been largely disconnected with practice - a trend which I find highly misguided and troubling. Nevertheless, the numbers of IS professors grew as the number of IS student majors grew. This trend continued until the early 2000s. Once the dot-com bubble burst, the completion of $\mathrm{Y} 2 \mathrm{~K}$ remediation work, and with the arrival of offshoring, IS student numbers collapsed. Public perception was that IS/IT jobs had disappeared, and what was left, would be offshored to India (or some other cheap labor destination). In essence, IS was no longer needed. And if IS was no longer needed at universities, there was no need for IS professors either. Some universities decided that IS was dead (or at best, on life support), and thus merged or closed some IS departments. What was once such a buoyant field, had become expendable. Universities had too many IS professors and were looking for ways to trim that number. IS faculty hiring essentially vanished.

Strangely, while the demand of IS PhDs dried up, the supply continued; even though universities were cutting IS programs, creating a surfeit of IS academics. Yet, the number of applicants to IS PhD programs changed little. Concomitant with the drop in demand for IS PhDs, was the cutting of state funding for universities. Universities have thus had to become creative in surviving in an era of ever decreasing state support. One proposed 'fix' was to obtain more research 
grants, requiring faculty to obtain research grant funding. This has led to a change in the reward system of professors even in disciplines who have not historically applied for research grants in the past, e.g. Business School professors. The question is: does this make sense? Consider, IS academia which has largely divorced itself from practice, most probably because such interaction wasn't rewarded by universities. Only top tier journal publications mattered. Now universities are saying they want research grants; especially from state and federal agencies so universities can take their $50 \%$ overhead charge. Research grants from industry are less appealing since most companies are not willing to support such high overhead rates; not to mention the 'problem' of the ownership of the intellectual property emerging from the research. Nor do companies see much value in working with academics whose research is seen as far removed from anything companies could use. (There are of course exceptions; cf. CIST at MIT, but such collaboration is rare.)

So where does this leave the IS Professor? The university wants skills which don't match the profession we aim to support, i.e. IS practitioners. The practitioner wants to interact with the IS professoriate only in so far that we - the academics - can produce graduates that they want to hire. Industry, for the most part, went away for much of the decade of 2000; but they are now coming back in droves, because they need IS employees, i.e. our graduates. They are not interested in our research. When companies are interested in having us do 'research' it is often of the market survey type, which is neither considered scholarly research by our peers, nor our main journals. Clearly the profession has a problem, but what possible solutions exist? I believe there are a number of possible strategies the field of academic IS can adopt:

- Bring individuals from industry into our PhD programs. Such individuals would add significantly to the overall blend of our IS PhD programs. Their knowledge of the key areas of what industry needs (and does not need) would help inform both the course content of what we teach as well as the research we undertake.

- Have PhDs take jobs in industry rather than only academia. In the US, it has been the case that our PhD graduates virtually always go into academia. Europe, and especially the German speaking community, have their graduates take jobs in industry. The value of this, is that managers in industry having $\mathrm{PhDs}$ are more likely to work with universities on research projects, and, more generally, be supportive of IS programs and IS professors. The professoriate in the US could learn a lot by studying how the German IS academic community works. It is a good model to base a revised IS program on.

- Summer IS professor interns. In the US, most IS professors are on nine month contracts, which means that the summer, professors are 'free' to do what they want. Of course they are not really 'free' as the summer is the key time where academics can devote full time to their research and publications. But suppose IS academics were offered summer internships in industry. This would help them learn more about industry and in particular what IS practitioners do and need, and this could help produce research programs that would get industry interested and possibly involved. When the summer intern idea was mentioned to a former Dean I had, he said that such an idea 'would be the death of any professor who took it'; meaning the professor would not engage in the kind of scholarly research needed for tenure and promotion. But why should applied research necessary mean 'unscholarly'. I believe IS Professors can do research which is rigorous, valuable, and publishable. MISQ Executive is an example of a publication outlet which should be valued by universities; and that IS academics should be encouraged to undertake research which can be published in such journals. This leads to my fourth point:

- Universities need to modify their reward system to support academics who work in Professional Schools/Disciplines, e.g. Business, Law, Medicine, Engineering, Music, etc. But such recognition must also include the realization that not all Professional Schools should be treated the same, i.e. use the same evaluation criteria. For example, Medicine and Engineering are different in that they have state and federal agencies, e.g. NSF, NIH, which fund their research. The same cannot be said with Business (or Music, etc.). IS Professors should not be expected to play on the same playing field as Engineering professors when it comes to research grants. Whilst research grants could be one metric for evaluation, it should not be the main source. Indeed, if it is used, it should be one of many criteria for evaluation. From a research standpoint, IS academics should be judged on their scholarly contributions, which are increasingly being measured by scientometic measure, numbers of citations, $h$ and $g$ indices, etc. In tenure and promotion decisions, hiring decisions, etc. committees look increasing at the citations and the h-index of a particular candidate. This trend is unlikely to abate.

- IS Professors need to realize that their world has changed, and we - as a community - need to adapt. This includes what we do our research on, what/how we teach, where we publish our research, who and how we interact with our different stakeholders/clients, etc. In particular, the IS academy needs to recognize and respond to the new fiscal realities of today's and tomorrow's universities. Gone are the 'good old days' where faculty pretty much had total control of what they did. This is no longer the case, and we need to evolve accordingly.

In closing, I still believe that being an IS Professor is a great job, but it has changed and we are not going back to the spectacular growth phase of the 1990s. We need to adapt or become extinct. The good news is that the field has shown that it can adapt, and I am optimistic that we can in the future as well.

\section{Prof. Dr. Dr. h. c. Rudy Hirschheim} Louisiana State University

\section{To Take a Chance on More Theory - Also in Business and Information Systems Engineering}

"The main challenge for a CEO is more than ever to cope with complexity" is a dictum by Franz Fehrenbach, chairman of the supervisory board of the Bosch Group. You would almost think that one of the most successful personalities in German economy is spelling the requirement profile of the business and information systems engineering (BISE) scientist here. Who could be more predestined to translate analyses into requirements, models into patterns, technologies into progress and products? Who else could bring into a business and its management the necessary "business intelligence" to stay on top of things in a closely linked world? 
First of all: Without doubt Fehrenbach's analysis is correct. Indeed, increasing complexity has enormously raised the requirements for the management of businesses: It has to cope with uncertainties and simultaneously mediate certainty; it has to plan and calculate without blindly following prognoses; it requires profound special and practicable knowledge and the ability to think interdisciplinarily. Whoever wants to balance these extremes needs personality, courage, intelligence, and a stable set of values? It is essential to take a position and have convictions - even when improving the use of IT in a business or aiming at more efficient management of IT-based businesses.

But are education in the universities and the qualification profile of our professors keeping in step? Should we follow the mainstream and call for more and more applied and practice orientation? In my opinion no; on the contrary: we should take a chance on more theory!

There are good reasons for this approach: The last years have shown that we no longer can rely on presumed certainties. Volatile markets, wavering moods, breaking trends, and - highly significant for IT - increasingly shorter intervals between technological steps: In these times of uncertainty, enduring fundamental strengths and weaknesses play a decisive role. The world is not "flat", as Thomas Friedman has stated. On the contrary: It is becoming more and more diversified and varied.

It is for this reason that we need teaching which enforces theory, a school of thought nurturing the ability for abstraction, analytic capabilities, and interdisciplinary reflection. I would even go a step further: not instruction is the goal, but education. Only the latter enables us to survive in a world changing ever faster. Who would for instance have thought ten years ago that the internet would really manage to revolutionize retailing or that data and applications would be once stored in the cloud and not on one's own server? That we would definitely abstain from atomic energy and that green technologies could determine our course of growth? Or that China would grow to the number one position in exports and that America would proclaim the "Pacific Age"? That the financial markets would get beyond control and thus cause the greatest economic crisis since the thirties?

This kind of complexity cannot be tackled with experience and knowledge acquired from case studies. What is needed today are sensitivity and personality, are scenarios to test ourselves with, are interdisciplinary knowledge and entrepreneurial intuition.

In this environment professors competent in theory can contribute their share by looking beyond the limits of their disciplines in research and teaching. In economic disciplines we need better linkage between

- Operational thinking: How to manage, how to set up a business correctly, how to gain lasting competitive advantages?

- Economic thinking: How does growth function, which patterns are behind it, where are their limits?

- Sociopolitical thinking: What are values, how do they change, what are the general trends and developments? And even

- Geopolitical thinking: Where are safety risks, how do countries and regions develop, what about regulation, what do political alliances mean, and much more?

When prognoses become invalid too fast or old patterns of explanation no longer give answers, we have to build our own opinion. The courage to do this is only summoned by those who have learned to broaden their outlook, to reflect, and to interrelate. Therefore theory oriented teaching is essential which features thinking patterns and analytic methods, poses critical questions concerning successful practices, and goes to the limits of conceptions and theories (self-critically asked: How often has IT really questioned a hype about a new technology?). I personally would add two elements to this position of theory orientation:

- A "studium fundamentale", which, following the ideas of Humboldt, begins with laying a philosophical basis, improving capabilities of reflection, including values, and conveying education.

- Broadly based studies from the beginning which include other disciplines in the case of BISE certainly economics and, as the circumstances require, subjects such as politics or sociology. Only in that way can we successfully recognize developments at an early stage and understand behavior and decisions of the stakeholders.

Taking a chance on more theory for me also means a high level of scientific excellence in our universities. If we in the long term want to safeguard not only the industrial competence which characterizes Germany and Europe, but also the capability to intelligently combine industrial know-how and service competence in systematic contracts, we do not only need good engineers and scientists, but to the same degree (more) excellence in economic sciences.

This is especially true for BISE. The requirements for this discipline - and its professors - should focus on the competence in theory and methods and not on contents oriented towards the mainstream or a presumed, always short-lived usefulness in practice. Instead of accepting the relativization of the educational ideals of Humboldt which has resulted from the introduction of Bologna, we should plead to return to these ideals in consideration of the circumstances. It will be crucial - in business and in science - to get a notion of one's own of the future instead of chasing after every trend. If we want to take on the great challenges of the world, we have to build bridges. More theory in BISE can substantially contribute to this goal.

Prof. Dr. Burkhard Schwenker Chairman

Roland Berger Strategy Consultants

\section{Contributions to Literature as Necessary but by No Means Sufficient Condition for an Offer of a University Professorship in Business and Information Systems Engineering}

The academic system in German speaking countries has seen quite a differentiation in the last years and decades. Apart from universities we now find technical colleges and in parts also goaloriented vocational academic institutions. Research and teaching as well as (in practice-relevant subjects) practice transfer are of course objectives for any kind of tertiary education. In detail, however, their profiles must show significant differences. Primary task for a university is the advancement of scientific progress, supplemented by research oriented teaching and the improvement of the transfer to practice of the latest results. A technical college should focus on the mediation of immediately usable knowledge, supplemented by the advancement of existing approaches combined with a comprehensive linkage to practice, assured by scientific methods. 
In a vocational academy teaching aspects would be still more strongly emphasized.

Without doubt all three types of advanced education find their justification. They be assessed according to different criteria, they should possess different structures, and, last but not least, should differ in their employment policies. For the employment of full-time professors, universities must pay special attention to previous and especially future contributions to the scientific progress, supplemented by an examination of abilities for research-oriented teaching and interaction with innovative practitioners. A university which in its employment strategy primarily focuses on excellence in teaching and practice transfer would not act according to its specific goals and thus question itself in the long run.

From a university's view, the question is how a scientist's previous and expected contributions to scientific progress are to be measured. Progress can mean a better understanding of the world and also its improvement. Many subjects (for example physics or philosophy) see their tasks primarily in the first field; others (such as technical sciences or medicine) tend to the second. Therefore one could expect that subjects with identical objectives would use the same indicators for the evaluation of research achievements. In reality, this is not the case! E.g., scientific progress in many technical disciplines is measured in the number of patents, whereas therapeutic progress in medicine normally is reflected in scientific publications.

The question now is what all these considerations mean for the employment policies of business and information systems engineering (BISE) faculties at universities. Following the differentiation shown above, academic BISE has to prove itself by means of its contribution to scientific progress, complemented by its contribution to research oriented teaching and interaction with innovative practitioners. In addition we must bear in mind that BISE, after a doubtlessly tantalizing self-reflecting process, considers itself as both explaining and designing. However, as in the field of medicine and thus different from technical disciplines, design-oriented contributions of BISE can be placed in publications. As a specialty of the discipline, scientific conferences as an out- let for research results have to be allowed for. Important impulses sometimes even come from books. The appearance in scientific publications and, though less important, in the proceedings of scientific conferences have therefore to be regarded as a necessary condition for the offer of employment as a university professor. For an impact analysis, publications in books should also be considered.

Especially in the comparison of applicants for a professorship, the question of concrete proof of each applicant's ability has to be posed. Here the assumption seems reasonable that the more often a scientific contribution is discussed in other scientific papers, the higher its value is. So-called impact marks therefore are important indications for a scientist's contribution. However, the reception of contributions takes some time. Therefore I believe that the use of relevant rankings for current research efforts in periodicals makes sense, especially for younger scientists. Both methods are superior to a subjective valuation by more or less specialized colleagues influenced by their own specific interests. In addition, they give orientation.

Both the impact analysis and the analysis of rankings have their weaknesses. Benchmarks are meaningful solely for comparisons inside a discipline. For this reason just a very general impression of a scientist's position of between international recognition and regional importance may be gained a more detailed positioning cannot be expected from the data. Both methods merely provide a picture of the past and therefore do not exempt from answering the question what kind of contributions are to be expected in future years, both from quite young and even more so from established scientists.

A scientist in BISE is sufficiently qualified if he can offer the desired achievements in research and if he in addition can also contribute to research oriented teaching and to interaction with innovative practitioners - a substitution of academic achievements by special excellence in teaching or in transfer is obviously excluded. In addition, management competence and the willingness to take on managerial tasks are essential in the system of chairs of a German university, an important condition not always automatically fulfilled when offering employment to scientists of foreign countries. Contributions to be expected in research oriented teaching may well be assessed by asking the applicant to present a teaching concept. Evaluations by students are not an apt indicator for teaching success and can merely be proof of pedagogical incompetence in case of negative results. The ability to interact with practitioners can be identified either by means of relevant contributions in publications for the practice or through the acquisition of funds from industry, both of course relating to the offered position.

Typically, a two-digit number of applications are received for every offer of a university chair, especially in BISE. It is not pragmatic and makes no sense to obtain all the mentioned information from each applicant. From experience it initially suffices to look at the necessary condition (documentation in literature), amended by formal criteria such as relevance of specialization and academic degrees. How high the bar is set depends upon the strategy of the university or of the faculty - the strategically relevant department of a research oriented university will act differently than an "additional department" of a small university. In a second step, the obtained "short list" of candidates can be checked more thoroughly for the necessary conditions. Apart from the academic discussion with the candidate, this should include reading various papers of the applicant, most appropriately proposed by himself. I also regard it wise to hand these on to an external reviewer.

Prof. Dr. Thomas Hess LMU München

\section{References}

\section{To: Section 1}

Acuna DE, Allesina S, Kording KP (2012) Future impact: predicting scientific success. Nature 489:201-202

Loos P, König W, Österle H, de Marco M, Pastor JA, Rowe F (2010) National research and international competitiveness - an antinomy? Business \& Information Systems Engineering 2(4):249-258

\section{To: Section 2}

Buhl HU, Fridgen G, Röglinger M, Müller G (2012) On dinosaurs, measurement ideologists, separatists, and happy souls. Business \& Information Systems Engineering 4(6):307-315 
Fischer K, Haerder M (2012) Von wegen Bildungsrepublik! Wirtschaftswoche, 2012-08-13. http://www.wiwo.de/ politik/deutschland/bildung-forschungund-hoersaal-beisammen-halten/ 6957094-5.html. Accessed 2012-12-06
Gill G, Bhattacherjee A (2009) Whom are we informing? Issues and recommendations for MIS research from an informing sciences perspective. MIS Quarterly 33(2):217-235
Mertens P (2011) Die Zielfunktion des Universitätslehrers der Wirtschaftsinformatik Setzen wir falsche Anreize? In: Bernstein A, Schwabe G (eds) Proc 10th international conference on Wirtschaftsinformatik, Zürich, vol 2, pp 1167-1175 